\title{
Entrepreneurship in the Microscopy Community
}

\author{
John Damiano ${ }^{1}$ \\ ${ }^{1}$ Protochips Inc., 3800 Gateway Centre Blvd., Morrisville, NC 27560
}

One highlight of the annual Microscopy \& Microanalysis meeting is visiting the exhibition floor and seeing the latest product offerings. For students, post-docs, and others in the field, working for one of the large, established microscopy companies is an attractive option. Others may choose to work in academia, or at a national lab or international research consortia. An alternative to all of these choices is entrepreneurship - starting a new venture, or working for an early-stage company. Small companies create millions of jobs and bring innovative products or services to the world, playing a vital role in all markets, including microscopy.

In this session, experienced company founders from the microscopy community will share their experiences and answer questions from the audience. Most prospective entrepreneurs ask common questions like:

What do I do? As an entrepreneur, you need to clearly understand the opportunity. Your product - whether new equipment, a new service, or a new workflow - must be differentiated from the competition and have a quantifiable advantage over existing technology. You will also need to build a clear case for customer return-on-investment (ROI) - why will costumers invest their money in what you're offering?

How do I get started? Founders may have a product concept, but it takes more than a good idea to get off the ground. Nothing happens without money, and finding a source of funding is essential. It's also helpful to connect with peers in both your market and in your local entrepreneurial community to build a network. You should identify thought leaders in the field to validate your assumptions about your product and the market. Finally, many local and state governments and non-profits offer a variety of programs dedicated to small business growth and to help connect entrepreneurs with resources.

How do I raise funding? Raising money is often the biggest challenge for founders. There are a number of ways to finance a business venture - savings, borrowing from relatives, government grants, and seed or venture capital. You will find that careful management of limited resources and deploying funds in a strategic way are essential.

How do I build a company? Many founders don't come from business backgrounds, so managing the growth of a company from founders to dozens of employees carries risk. You will need to build out a team to complement the experience of the founders and add critical skills. How do you scale operations to meets sales growth? If your market is international, how do you approach a world of customers with different expectations and different needs? All of this requires careful strategic planning. 
Each company story is different, but all can provide useful lessons. Protochips started when its founders were graduate students in the same research group who, having all worked in industry before returning to graduate school, bonded over our common interest in MEMS design and entrepreneurship. After an initial foray into small-scale foundry work, we decided to focus on opportunities in electron microscopy. Inexpensive sample supports and two Phase I/II SBIR grants provided funding for the development of more powerful and complex systems. Protochips is now a leading vendor of solutions for in situ electron microscopy. A larger presence at M\&M (Figure 1), improved marketing materials (Figure 2), and a strong publication track record are the most visible signs of growth.

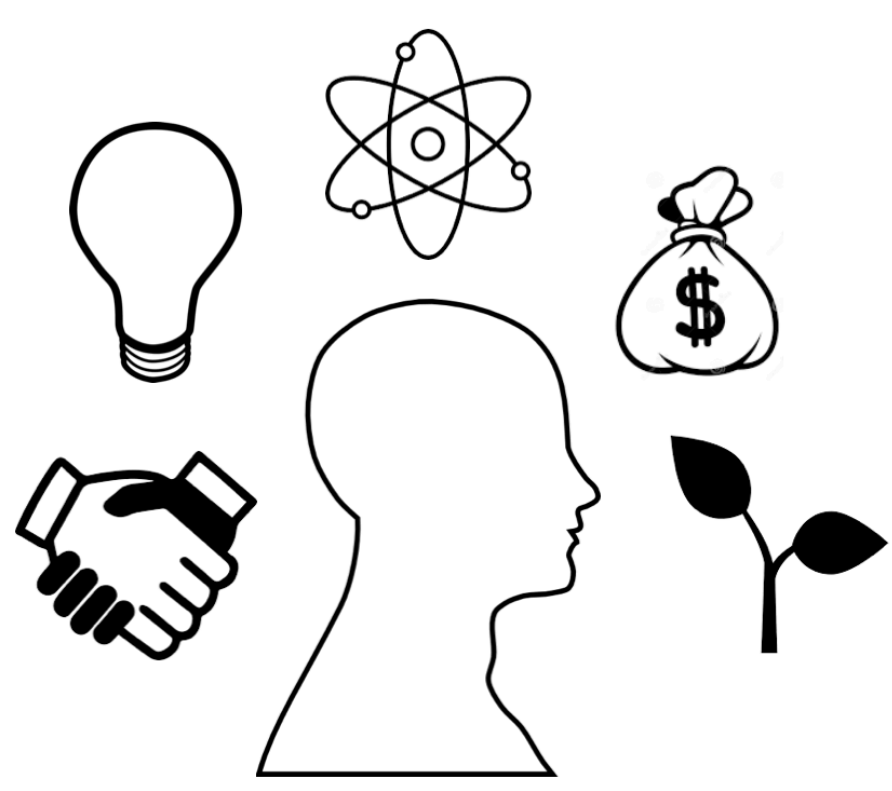

Please join this session and hear a panel of entrepreneurs present their "lessons learned" and share their stories with the community. I look forward to seeing you there!
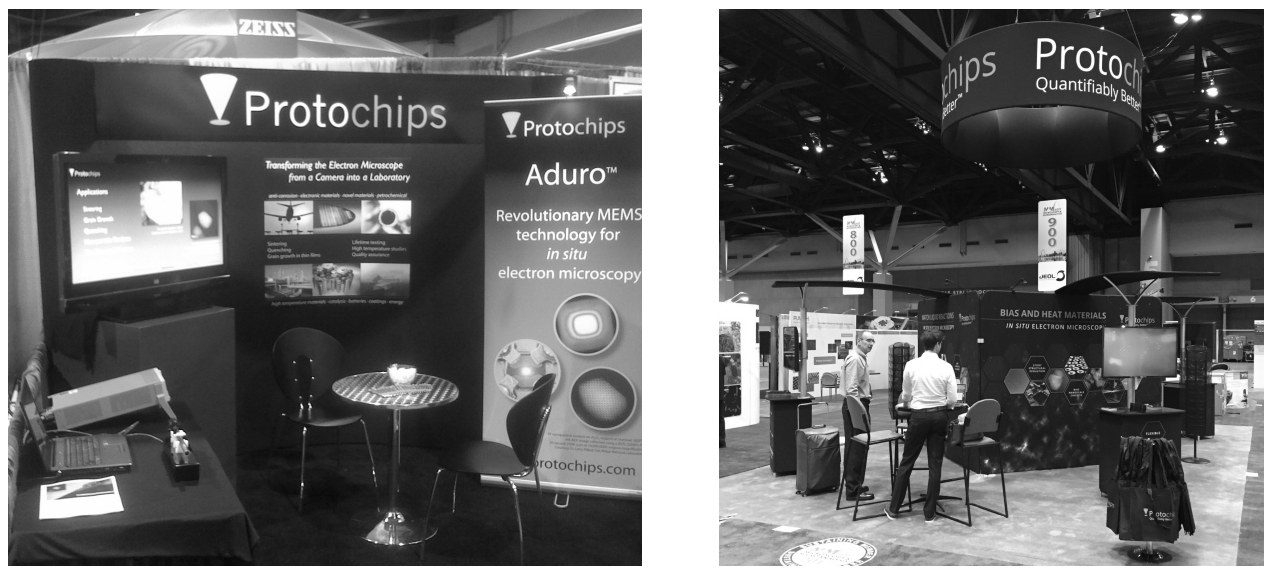

Figure 1. Protochips M\&M booth in 2008 (left) and 2017 (right).
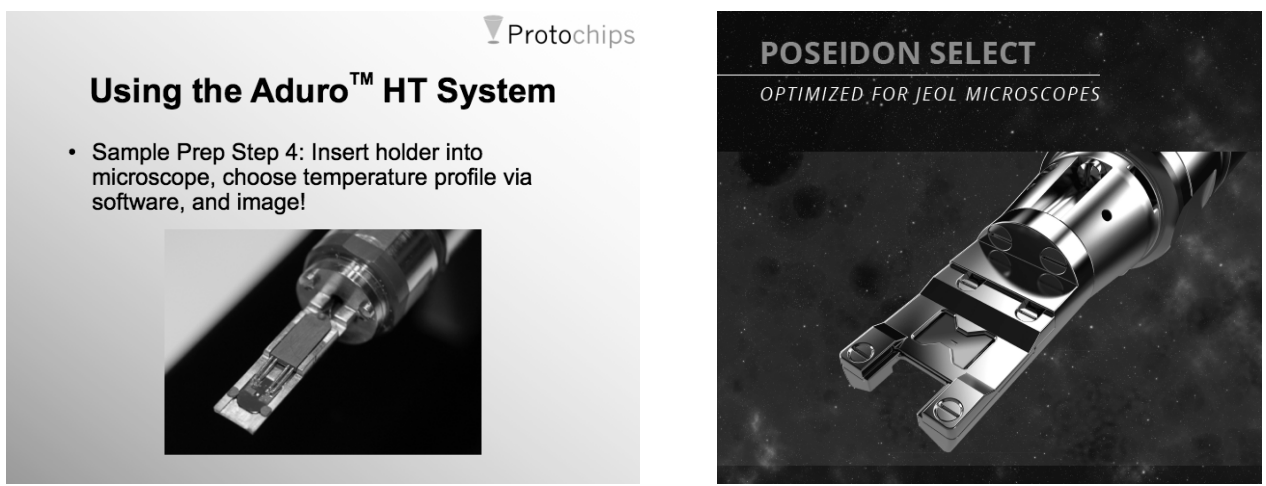

Figure 2. Protochips marketing materials in 2009 (left) and 2017 (right). 